\title{
A Solution to Remove Railway Track Discontinuities at Spiral Junctions
}

\author{
Jean-Pierre Pascal \\ Laboratoire de Mécanique et Génie Civil, Université de Montpellier, Montpellier, France \\ Email address: \\ Pascal.voc@wanadoo.fr

\section{To cite this article:} \\ Jean-Pierre Pascal. A Solution to Remove Railway Track Discontinuities at Spiral Junctions. International Journal of Mechanical \\ Engineering and Applications. Vol. 8, No. 4, 2020, pp. 95-102. doi: 10.11648/j.ijmea.20200804.11
}

Received: September 2, 2020; Accepted: September 17, 2020; Published: September 24, 2020

\begin{abstract}
To design railway track layouts, engineers use tangent and circle segments. To maintain curvature and bank angle continuities between flat straight lines, with zero curvature, and banked circles, they use spiral segments where curvature and bank angle vary linearly as function of distance. This method meets the behavior of track engineers for which curvature and super-elevation are the main data used to lay the groundwork. However, it demonstrates dynamical drawbacks at both ends of spirals where bank angle and curvature derivatives would be discontinuous. Several unsuccessful attempts have been made to change spirals definition to alleviate this issue. In reality, track engineers smoothen the theoretical layout at the junctions, but there is no analytical definition for that although it is necessary track data at least for simulation codes. Smoothing portions are called 'doucines' but the maps of railway lines do not mention these unknown data and railway numerical codes ignore them, thus having to deal with subsequent dynamical perturbations which are avoided by doucines in reality. This paper proposes an analytical definition of practical doucines which does not modify actual theoretical method for designing lines. It also describes a method for programming it in railway codes. It uses trigonometric functions, sine and cosine which are simple to integrate to get at first the track orientation and then the X-Y coordinates of the layout line. In addition to doucine definitions, usable as well in practice as for all multibody codes, the paper shows how it can be implemented into the specific French calculation method, which uses an imaginary space, developed at first for calculating the dynamics of TGV. After modifying the author's Ocrecym code according to the proposed doucine method, dynamical simulations of a light trailer coach, running over curved lines with and without doucines are presented to demonstrate the effectiveness of proposed solution.
\end{abstract}

Keywords: Railway Tracks, Track Layout, Dynamical Perturbations, Spirals, Doucines, Multibody Codes

\section{Introduction}

Fifty years ago, passenger trains devoted to high speed lines were developed in Europe and in Japan. Due to higher speeds, concomitant dynamical issues increased together with the need for mathematical simulations taking into account the geometric quality of tracks. Simultaneously, the fast development of computers and mainly also the publication of Professor Kalker thesis [1] which allowed to calculate precisely contact forces between wheels and rails, permitted researchers to develop powerful numerical multibody codes [2]. These codes need tracks data as inputs; data are of two types, either in the form of point to point numerical files coming from direct measurements of actual tracks, or in the form of the theoretical layout such as registered on the maps. Since getting actual track measurements is not always easy, theoretical layouts are largely used in simulations.

To design railway track layouts, engineers assemble tangent and circle segments. In order to maintain curvature and bank angle continuities between flat straight lines, with zero curvature, and banked circles, they use spiral segments. In the past, many attempts have been made to develop more or less complicated definitions of spirals [3-5], some used polynomial functions [5], others versine functions [3] but from more than 50 years, in practice, curvature and bank angle of spirals vary linearly as function of distance. This method meets the behavior of track engineers for which curvature and super-elevation are the main data used to lay the groundwork (Figure 1).

In mathematics, such spirals are called 'clothoïds' or 'Euler spirals' and, although it may look strange, because 
largely used in practice, nobody ever could calculate the X-Y function representing it; $\mathrm{Y}=\mathrm{f}(\mathrm{X})$ has to be calculated by double integration of the curvatures, at first by integrating the linear curvature to find the direction of the tangent and secondly by integrating this angle to calculate $\mathrm{X}$ and $\mathrm{Y}$ coordinates.

However, the linear method demonstrates dynamical drawbacks at both ends of spirals where bank angle and curvature derivatives would be discontinuous $[4,15]$. To alleviate this issue, track engineers smoothen theoretical layouts at the junctions $[6,14]$ but there is no analytical definition of these adjustments although it would be necessary to introduce exact track data in simulation codes. The smoothing portions are called 'doucines' but the maps of railway lines do not mention these unknown data and railway numerical codes must ignore them, thus having to deal with subsequent dynamical perturbations at segment junctions.

In order for a point of mass $\mathrm{M}$ to follow the line of curvature $C(x)$ at the constant longitudinal speed $\mathrm{Vx}$, it is necessary to apply to $\mathrm{M}$ a force $F c$ always directed toward the curvature center and of magnitude:

$$
F c=\mathrm{M} \cdot \mathrm{Vx}^{2} \cdot C(x)
$$

For $\mathrm{Fc}$ to be continuous it is necessary that $C(\mathrm{x})$, bank angle $\phi(x)$ and their derivatives be continuous. The Figure 1 shows the discontinuities of derivatives at junction points.

For a spiral of length SL beginning at abscissa $\mathrm{x} 0$, between a tangent and a circle of curvature $\mathrm{Cc}$ we have:

$$
C(x)=\mathrm{Cc} / \mathrm{SL} .\left(\mathrm{x}-\mathrm{x}_{0}\right),\left[\mathrm{x}_{0}<\mathrm{x}<\mathrm{SL}+\mathrm{x}_{0}\right]
$$

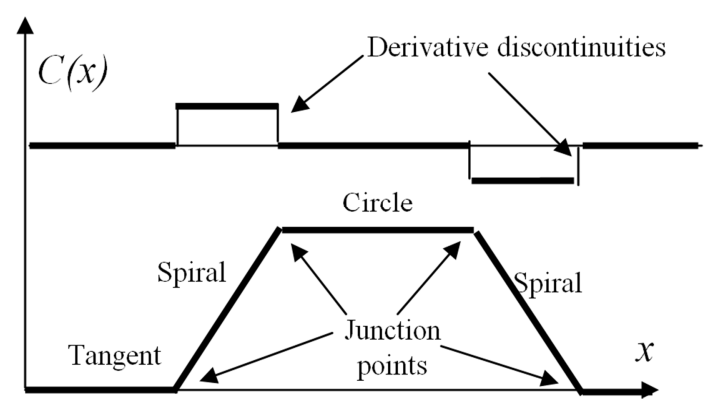

Figure 1. Theoretical variation of curvatures $C(x)$ between tangents and circles (same sketch for bank angles).

All dynamical codes rely upon Newton equations written in a Galilean space (global space), but, not only the force $\mathrm{Fc}(\mathrm{x})$, equation (1), is variable in direction but also the angles of this direction increase well further first order approximations. Thus calculations in the global space necessitate to use continuously changing rotation matrices with sines and cosines so that numerical calculations of complex vehicles, having several solid bodies linked by numerous oriented springs and dampers, become quickly problematic after few seconds of simulations (matrices are often ill conformed).

For avoiding these issues, in French railway codes, calculations are made in an imaginary space where the centripetal force $\mathrm{Fc}$ does not rotate [7-8].

\section{Imaginary Space (Figure 2)}

For dynamical studies of the French TGV, from years 1980, we developed the multibody code VOCODYM (INRETS-SNCF) [9] which works owing to a space transformation from Cartesian global space (O X Y) to an imaginary Cartesian space (O S $\left.\mathrm{Y}^{*}\right)$ in which is build an image $\mathrm{Y}^{*}(\mathrm{~S})$ of the actual line $\mathrm{Y}(\mathrm{x})$. This image owns the following main properties:

In order that point $\mathrm{M}$ follow the line $\mathrm{Y}^{*}(\mathrm{x})$ it is necessary to apply a no rotating force $\mathrm{Fc}(\mathrm{x})$ of same modulus as the centripetal force and of constant direction parallel to OY* axis (Figure 2). Gyroscopic moments and Coriolis forces are added owing to classical mechanics formula [10].

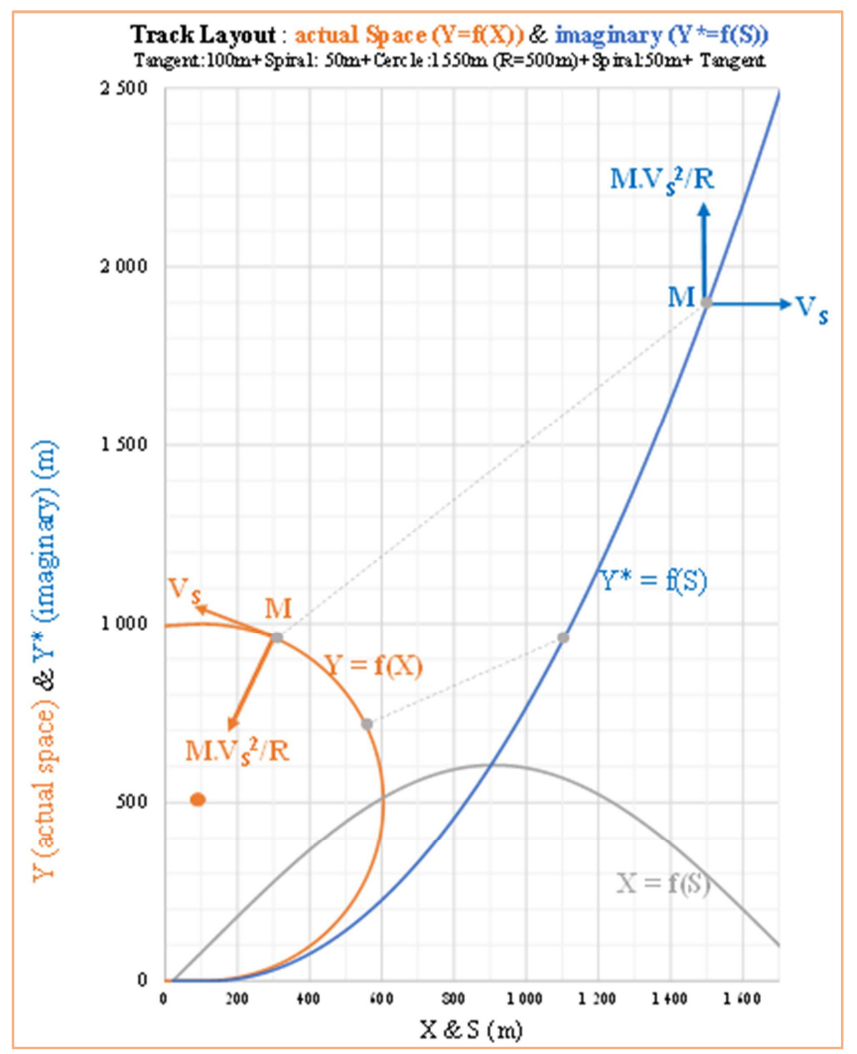

Figure 2. How a real curve (orange line) becomes the blue image which $M$ follows owing to same 'centripetal' force as in the real curve but having now a constant direction.

The abscissa $\mathrm{S}$ of the line in (O S Y*) space equals the arc length on the actual line so that the speed Vx is directed along this abscissa axis OS.

Notations: unless otherwise mentioned, the Cartesian $\mathrm{x}$ coordinate of the global space being not further used below, in accordance with the usual speed notation $\mathrm{Vx}$, it will be more comfortable to use $\mathrm{x}$ instead of $\mathrm{S}$ in this paper from this point on for the abscissa in the imaginary space.

This transformation owns other properties which largely simplify calculations:

1) Defining the imaginary line necessitates only to know its actual curvature $C(x)$

2) The angle $a t(x)$, direction of the tangent to the actual curve is equal to the first integral of $C(x)$ : 


$$
a t(x)=\int_{x o}^{x} C(x) \cdot d x+A 1
$$

3) The ordinate $y^{*}(x)$ of the imaginary line is given by the integral of this angle $\operatorname{at}(x)$ :

$$
y *(x)=\int_{x o}^{x} a t(x) \cdot d x+A 1 \cdot x+\mathrm{Y} 1
$$

4) The abscissa $x$ of the image equals the distance $S$ :

$$
x(t)=\int_{t o}^{t} V x(t) \cdot d t
$$

\section{How to Apply It in an Example}

The spiral of length SL begins at abscissa $\mathrm{x} 1$ and ends at $\mathrm{x} 2$ where begins the circle of length CL which ends at $\mathrm{x} 3$ and the second spiral ends at $\mathrm{x} 4$ (Figure 4).

\subsection{First Tangent Segment (Subscript: t)}

$$
\mathrm{C}_{\mathrm{t}}(\mathrm{x})=0, \mathrm{at}_{\mathrm{t}}(\mathrm{x})=\mathrm{y}_{\mathrm{t}}^{*}(\mathrm{x})=0
$$

\subsection{First Spiral Segment (Subscript 1)}

length $\mathrm{SL}_{1}$ (no doucines)

begins at $\mathrm{x}=\mathrm{x} 1$

maximum curvature at $\mathrm{x} 2 \mathrm{Cc}$

slope of the curvature:

$$
\mathrm{pc}=\mathrm{Cc} / \mathrm{SL}_{1}
$$

curvature:

$$
C c(x)=\text { pc. }(x-\mathrm{x} 1)
$$

tangent angle and $\mathrm{y}^{*}$ :

$$
\begin{aligned}
& a t_{1}(x)=\int_{x 1}^{x} C(x) \cdot d x+\mathrm{A} 1=\text { pc } \cdot \frac{x^{2}}{2}-\text { pc. } x_{1} \cdot x+\mathrm{A} 1 \\
& Y_{1}^{*}(x)=\int_{x 1}^{x} a t(x) \cdot d x+\mathrm{A} 1 \cdot x+\mathrm{Y}_{1}^{*}=p c \cdot \frac{x^{3}}{6}-p c \cdot x_{1} \cdot \frac{x^{2}}{2}+\mathrm{A} 1 \cdot x+\mathrm{Y}_{1}^{*}
\end{aligned}
$$

\subsection{Circle Segment, $[x 2<x<x 3], C(x)=$ Cc (Subscript: 2)}

length CL (no doucines)

$$
\mathrm{x} 2=\mathrm{x} 1+\mathrm{SL}_{1}
$$

tangent angle and $\mathrm{y}^{*}$ :

$$
\begin{gathered}
a t_{2}(x)=\int_{x_{2}}^{x} C(x) \cdot d x+\mathrm{A} 2=\text { Cc. } x+\mathrm{A} 2 \\
Y_{2}^{*}(x)=\int_{x_{2}}^{x} a t_{2}(x) \cdot d x=\text { Cc. } \frac{x^{2}}{2}+\mathrm{A} 2 \cdot x+\mathrm{Y}_{2}^{*}
\end{gathered}
$$

3.4. Continuities: Calculation of Constants $A 1, Y_{1}^{*}, A 2, Y_{2}^{*}$ :

$$
\text { At x1: } a t_{1}\left(x_{1}\right)=0=\text { pc. } \frac{x_{1}^{2}}{2}-\text { pc. } x_{1}^{2}+\mathrm{A} 1
$$

hence: $\mathrm{A} 1=$ pc. $\frac{x_{1}^{2}}{2}(12)$

$$
Y_{1}^{*}\left(x_{1}\right)=0=\text { pc. } \frac{x_{1}^{3}}{6}-\text { pc. } \frac{x_{1}^{3}}{2}+\mathrm{A} 1 \cdot x_{1}+\mathrm{Y}_{1}^{*}
$$

thus:

$$
\mathrm{Y}_{1}^{*}=\text { pc. } x_{1}^{3}-\text { pc. } \frac{x_{1}^{2}}{2} \cdot x_{1}=\text { pc } \frac{x_{1}^{3}}{2}
$$

At $\mathrm{x} 2: a t_{1}\left(x_{2}\right)=$ pc. $\frac{x_{2}^{2}}{2}-$ pc. $x_{1} \cdot x_{2}+\mathrm{A} 1=a t_{2}\left(x_{2}\right)$

$$
a t_{2}\left(x_{2}\right)=\text { Cc. } x_{2}+\mathrm{A} 2
$$

Thus:

$$
\begin{gathered}
\mathrm{A} 2=\text { pc } \frac{x_{2}^{2}}{2}-\text { pc. } x_{1} \cdot x_{2}+\text { pc. } \frac{x_{1}^{2}}{2}-\text { Cc. } x_{2} \\
Y_{1}^{*}\left(x_{2}\right)=\text { pc. } \frac{x_{2}^{3}}{6}-\text { pc. } x_{1} \cdot \frac{x_{2}^{2}}{2}+\mathrm{A} 1 \cdot x_{2}+\mathrm{Y}_{1}^{*}= \\
Y_{2}^{*}\left(x_{2}\right) Y_{2}^{*}\left(x_{2}\right)=\text { Cc. } \frac{x_{2}^{2}}{2}+\mathrm{A} 2 \cdot x_{2}+\mathrm{Y}_{2}^{*}, \text { thus: } \\
\mathrm{Y}_{2}^{*}=\text { pc. } \frac{x_{2}^{3}}{6}-\text { pc. } x_{1} \cdot \frac{x_{2}^{2}}{2}+\mathrm{A} 1 \cdot x_{2}+\mathrm{Y}_{1}^{*}-\mathrm{Cc} \cdot \frac{x_{2}^{2}}{2}-\mathrm{A} 2 \cdot x_{2}
\end{gathered}
$$

\subsection{Calculation of Subsequent Segments}

The same method is used to calculate the functions $a t_{n}(x)$ and $Y_{n}^{*}(x)$. Both associated constants for each new segment, $\mathrm{A}_{\mathrm{n}}$ and $\mathrm{Y}_{\mathrm{n}}^{*}$, are calculated the same way in order to assume continuities at junctions.

All these functions have been coded in VOCODYM [9] and OCRECYM [10] $]^{1}$ codes in order being able to simulate any lines made of consecutive segments, straight lines, spirals and circles.

\subsection{Example of the Figure 2}

This example is meant to show both spaces, actual and imaginary, on the same plot. To show well separated lines, the circle length is $\pi$ times its radius $(\mathrm{R}=500 \mathrm{~m})$ and shapes a semi-circle. $\mathrm{X}$ is used as abscissa of the real line and its length of arc $\mathrm{S}$ is used as abscissa of the imaginary line:

$\begin{array}{llll}\text { tangent: } & 100 \mathrm{~m} & \mathrm{~S} 1=100 \mathrm{~m} & \mathrm{X} 1=100 \mathrm{~m} \\ \text { spiral: } & 50 \mathrm{~m} & \mathrm{~S} 2=150 \mathrm{~m} & \mathrm{X} 2=129 \mathrm{~m} \\ \text { circle: } & 1550 \mathrm{~m} & \mathrm{~S} 3=1700 \mathrm{~m} & \mathrm{X} 3=100 \mathrm{~m} \\ \text { spiral: } & 50 \mathrm{~m} & \mathrm{~S} 4=1750 \mathrm{~m} & \mathrm{X} 4=50 \mathrm{~m}\end{array}$

tangent:

The orange line in real space, $\mathrm{Y}=\mathrm{f}(\mathrm{X})$, is coming from numerical integrations of the angle $a t(x)(6-15)$ :

$$
\mathrm{X}=\sum_{0}^{S} \cos (a t) \cdot \mathrm{d} S \& \mathrm{Y}=\sum_{0}^{S} \sin (a t) \cdot \mathrm{d} S
$$

The distance $\mathrm{S}$ is resulting from time integration of the constant speed Vx.

\subsection{Dynamical Perturbations at Segments Junctions}

Although many proper simulations have been calculated using such theoretical track layouts, there remains the drawback of generating improper accelerations at segment junctions, knowing that, in practice, the sharpness of these junctions is smoothen using doucines on groundworks.

1 The SNCF-INRETS code Vocodym was developed around 1980 and equivalent wheel-rail contacts were pre-calculated in tables; Ocrecym was developed by J.P. Pascal around 2005 and uses the online Ocrec contact method [13] 
That is the reason for the proposal of an analytical definition of doucines usable in numerical codes and possibly in actual lines.

\section{New Proposal for Doucines Definition}

This proposal is intended both to cancel discontinuities of curvature and bank angle derivatives at segment junctions without modifying the theoretical layout of the line like is done in practice. To this end, we add new 'doucine' segments in between already described line segments but without modifying the overall layout (Figures 3-4). Like spirals, the doucine curves are defined by their curvature which we choose as a trigonometric function of distance:

$$
C(x)=\mathrm{A} \cdot\left( \pm \operatorname{sine}\left(2 \cdot \pi \cdot\left(\mathrm{x}-\mathrm{x}_{\mathrm{n}}\right) / \lambda\right) \pm 1\right) \text { or } C(x)=\mathrm{A} \cdot\left( \pm \operatorname{cosine}\left(2 \cdot \pi \cdot\left(\mathrm{x}-\mathrm{x}_{\mathrm{n}}\right) / \lambda\right) \pm 1\right)
$$

Such functions are easily derivable and integrable analytically. They own the adjustable parameter, A, necessary for building continuity with adjacent segments and the wavelength $\lambda$ can be adjusted to modify doucine's sharpness (doucine length).

The doucine length being $\mathrm{DL}=\left(\mathrm{x}_{\mathrm{n}+1}-\mathrm{x}_{\mathrm{n}}\right)$, the wavelength $\lambda$ is set at 4 . DL so that sine or cosine be either 1 or 0 at both end junctions $\mathrm{x}=\mathrm{x}_{\mathrm{n}}($ sine $=0$ \& cosine $=1)$ or $\mathrm{x}=\mathrm{x}_{\mathrm{n}+1}(\operatorname{sine}=1 \&$ cosine $=0$ ).

The Figures 3 and 4 show an example of a track with doucines:

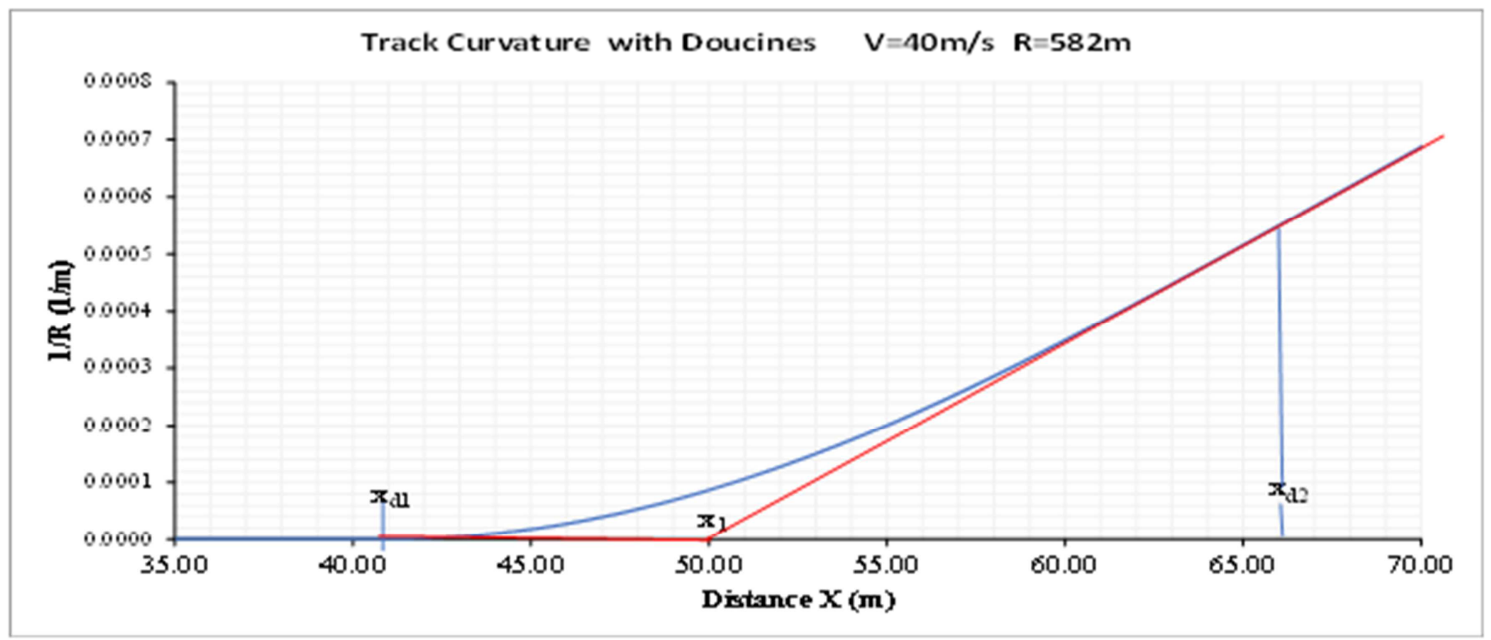

Figure 3. The blue doucine starts at $X_{d 1}$ and ends at $X_{d 2}$ when the clothoid spiral was intended to begin at $X_{1}$.

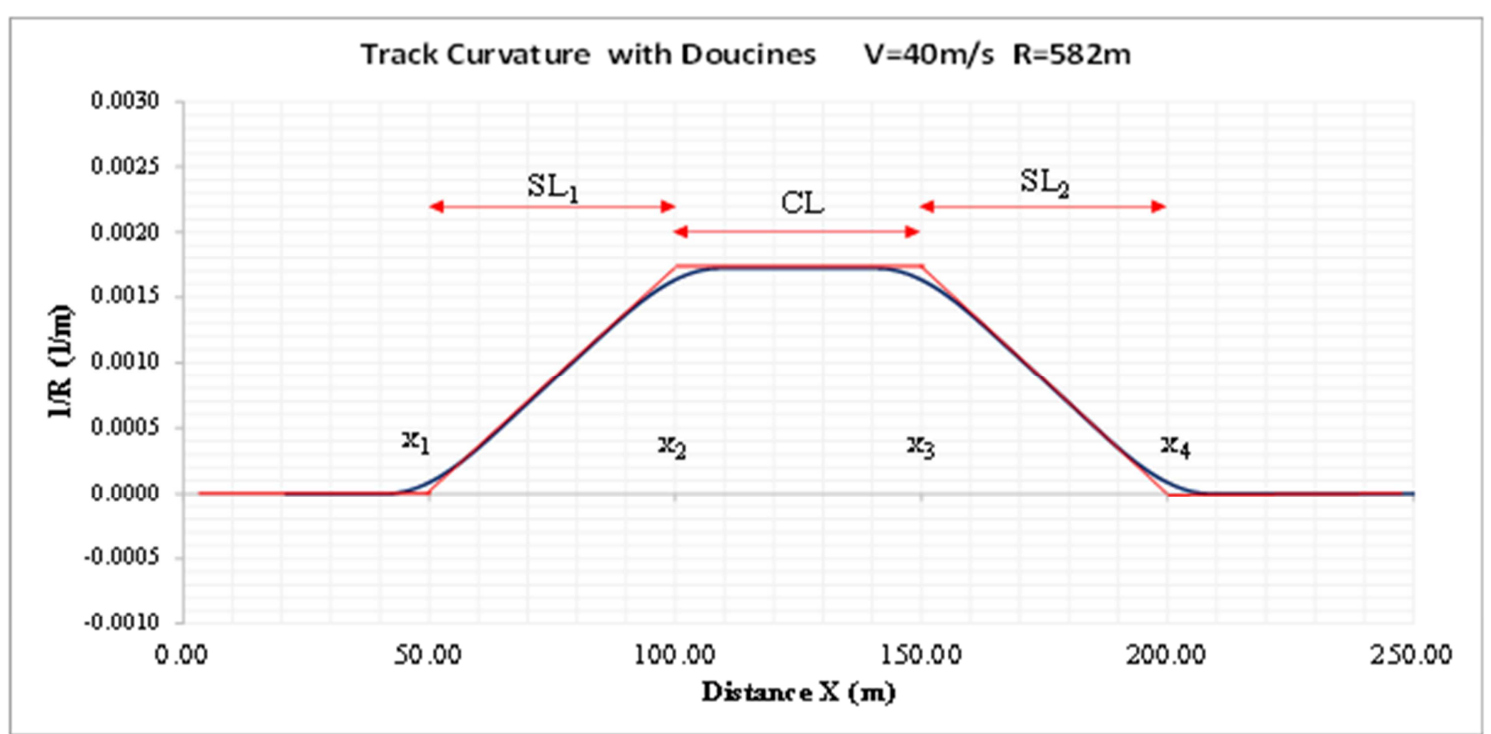

Figure 4. Four doucines between five segments; note that initial junction abscissae and spiral slopes are not modified.

\section{Parameters for Doucines Continuity}

\subsection{First Doucine $\left[x_{d 1}<x<x_{d 2}\right]$}

Constants are calculated for maintaining the continuity with adjacent segments:

$$
\begin{gathered}
C d_{1}(x)=\text { H. }\left(1-\cos \left(\text { FRQ } \cdot\left(\mathrm{x}-\mathrm{x}_{\mathrm{d} 1}\right)\right)\right) \\
\mathrm{FRQ}=2 \cdot \pi / \lambda
\end{gathered}
$$


Derivative (slope):

$$
\left.\left.p_{d 1}(x)=\text { H.FRQ.sin(FRQ. }\left(\mathrm{x}-\mathrm{X}_{\mathrm{d} 1}\right)\right)\right)
$$

for better continuity it is set:

$$
\text { FRQ. }\left(\mathrm{x}_{\mathrm{d} 2}-\mathrm{x}_{\mathrm{d} 1}\right)=\pi / 2
$$

Hence:

$$
\mathrm{x}_{\mathrm{d} 2}=\mathrm{x}_{\mathrm{d} 1}+\lambda / 4
$$

at $\mathrm{x}_{\mathrm{d} 1}$, tangent slope: 0 doucine slope: 0

at $\mathrm{x}_{\mathrm{d} 2}$, clothoïd slope: $\mathrm{pc}=\mathrm{Cc} / \mathrm{SL}$,

doucine slope: H.FRQ hence:

$\mathrm{H}=\mathrm{pc} / \mathrm{FRQ}=\mathrm{Cc} /(2 . \pi . \mathrm{SL} / \lambda)$

We set: $\lambda=\mathrm{k} . \mathrm{SL},(0.3<\mathrm{k}<3)$, hence:

$$
\mathrm{H}=\mathrm{k} . \mathrm{Cc} / 2 . \pi \text {. }
$$

at $\mathrm{x}_{\mathrm{d} 2}: \mathrm{Cc}\left(\mathrm{x}_{\mathrm{d} 2}\right)=$ pc. $\left(\mathrm{x}_{\mathrm{d} 2}-\mathrm{x}_{1}\right)$ and $\mathrm{Cd}\left(\mathrm{x}_{\mathrm{d} 2}\right)=\mathrm{H}$, hence:

$\mathrm{H}=\operatorname{pc} .\left(\mathrm{x}_{\mathrm{d} 2}-\mathrm{x}_{1}\right)$ and from $(21)$

$$
\mathrm{x}_{\mathrm{d} 2}=\mathrm{x}_{1}+\mathrm{H} / \mathrm{pc}=\mathrm{x}_{1}+\mathrm{k} . \mathrm{SL} / 2 . \pi .
$$

and from (20):

$$
\mathrm{x}_{\mathrm{d} 1}=\mathrm{x}_{1}+\mathrm{k} . \mathrm{SL} / 2 . \pi .-\mathrm{k} . \mathrm{SL} / 4=\mathrm{x}_{1}-0.090845 . \mathrm{k} . \mathrm{SL}
$$

We will not derive here same calculations that must be made for all doucines. We give their curvatures:

\subsection{Second Doucine $\left[x_{d 3}<x<x_{d 4}\right]$}

$$
C d_{2}(x)=\mathrm{Cc}+\mathrm{H} .\left(\sin \left(\mathrm{FRQ} \cdot\left(\mathrm{x}-\mathrm{x}_{\mathrm{d} 4}\right)\right)-1\right)
$$

5.3. Third Doucine $\left[x_{d 5}<x<x_{d 6}\right]$

$$
C d_{3}(x)=\mathrm{Cc}+\mathrm{H} \cdot\left(\cos \left(\mathrm{FRQ} \cdot\left(\mathrm{x}-\mathrm{x}_{\mathrm{d} 5}\right)\right)-1\right)
$$

\begin{tabular}{|c|c|c|c|}
\hline tangent: & $50 \mathrm{~m}$ & $\mathrm{X} 1=50 \mathrm{~m}$ & \\
\hline spiral: & $50 \mathrm{~m}$ & $\mathrm{X} 2=100 \mathrm{~m}$ & \\
\hline circle: & $50 \mathrm{~m}$ & $\mathrm{X} 3=150 \mathrm{~m}$ & $\mathrm{R}=582.1 \mathrm{~m}\left(3^{\circ}\right)$ \\
\hline $\begin{array}{l}\text { spiral: } \\
\text { tangent: }\end{array}$ & $50 \mathrm{~m}$ & $\mathrm{X} 4=200 \mathrm{~m}$ & \\
\hline
\end{tabular}

5.4. Fourth Doucine $\left[x_{d 7}<x<x_{d 8}\right]$

$$
C d_{4}(x)=\mathrm{H} \cdot\left(1-\cos \left(\mathrm{FRQ} \cdot\left(\mathrm{x}_{\mathrm{d} 8}-\mathrm{x}\right)\right)\right)
$$

\section{Dynamical Simulation Results Using OCRECYM Code [13]}

\subsection{Parameters of the Track Layout}

\subsection{Vehicle}

The vehicle is a light coach of $40600 \mathrm{~kg}$ with 2 bogies and 4 wheelsets:

wheelsets distance: $2.56 \mathrm{~m}$

bogies distance: $18.3 \mathrm{~m}$

wheels profiles: $\mathrm{S} 1002$

Rail profiles: UIC 60 @1/40 (conformal pair) [11].

$\begin{array}{ll}\text { primary } & \mathrm{kx}=6 . \mathrm{E} 7 \mathrm{~N} / \mathrm{m}, \\ \text { suspension } & \mathrm{ky}=4.8 \mathrm{E} 6 \mathrm{~N} / \mathrm{m} \\ & \mathrm{kz}=8.5 \mathrm{E} 5 \mathrm{~N} / \mathrm{m}, \mathrm{cz}=2 . \mathrm{E} 4 \mathrm{~N} / \mathrm{m} / \mathrm{s} \\ \text { secondary } & \mathrm{kx}=1.7 \mathrm{E} 5 \mathrm{~N} / \mathrm{m} \\ \text { suspension } & \mathrm{ky}=1.7 \mathrm{E} 5 \mathrm{~N} / \mathrm{m} \\ & \mathrm{kz}=4 . \mathrm{E} 5 \mathrm{~N} / \mathrm{m}, \mathrm{cz}=1.2 \mathrm{E} 4 \mathrm{~N} / \mathrm{m} / \mathrm{s}\end{array}$

\subsection{Simulations at $40 \mathrm{~ms}(90 \mathrm{mph})$}

The carbody Vx speed is constraint at $40 \mathrm{~m} / \mathrm{s}$.

The sensible output results are wheelsets and bogies accelerations which are measured in a moving reference frame having OZ vertical, OY and OX horizontal.

In this simulation we have plotted, on the Figure 5, the first wheelset lateral acceleration, with doucines (blue line) and without doucine (red line). The large red line peaks at segment junctions are removed using doucines. Even the small perturbation at abscissa $60 \mathrm{~m}$, due to the wheel flange contact with the rail (Figure 6) is attenuated by the doucines.

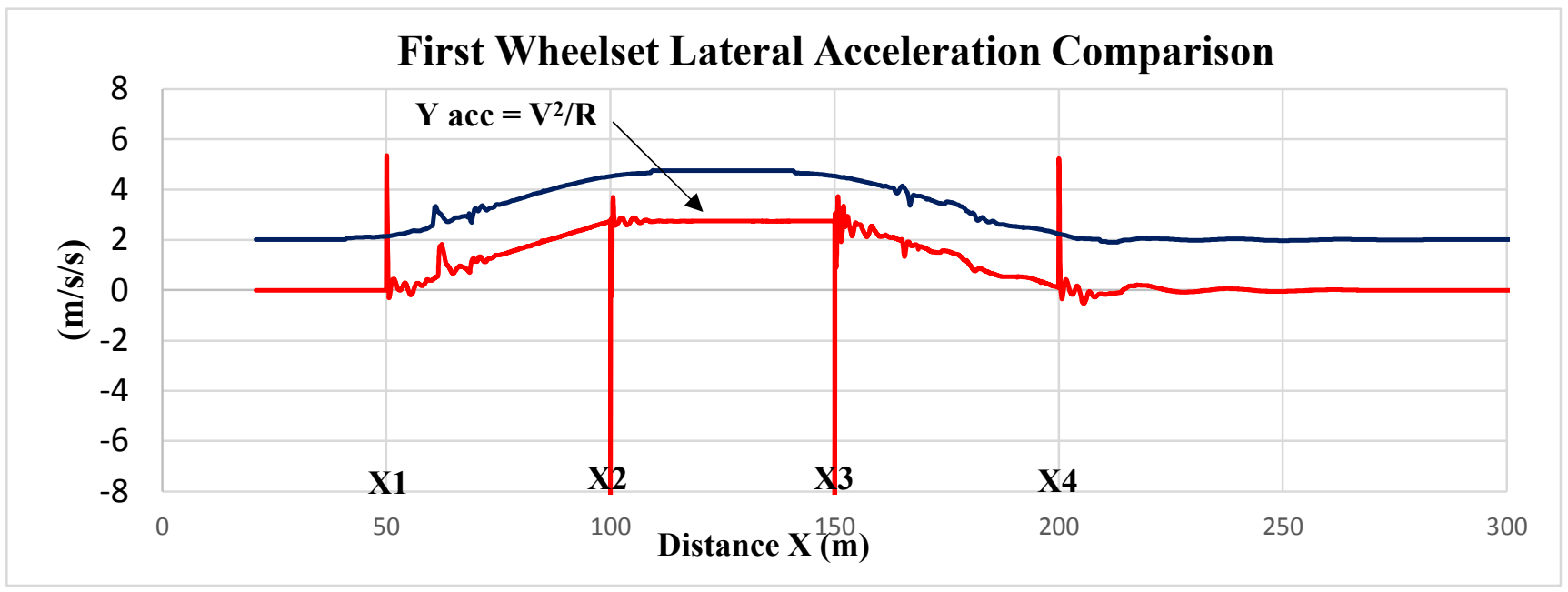

Figure 5. Comparison of wheelset lateral accelerations with (shifted up) and without doucines. 


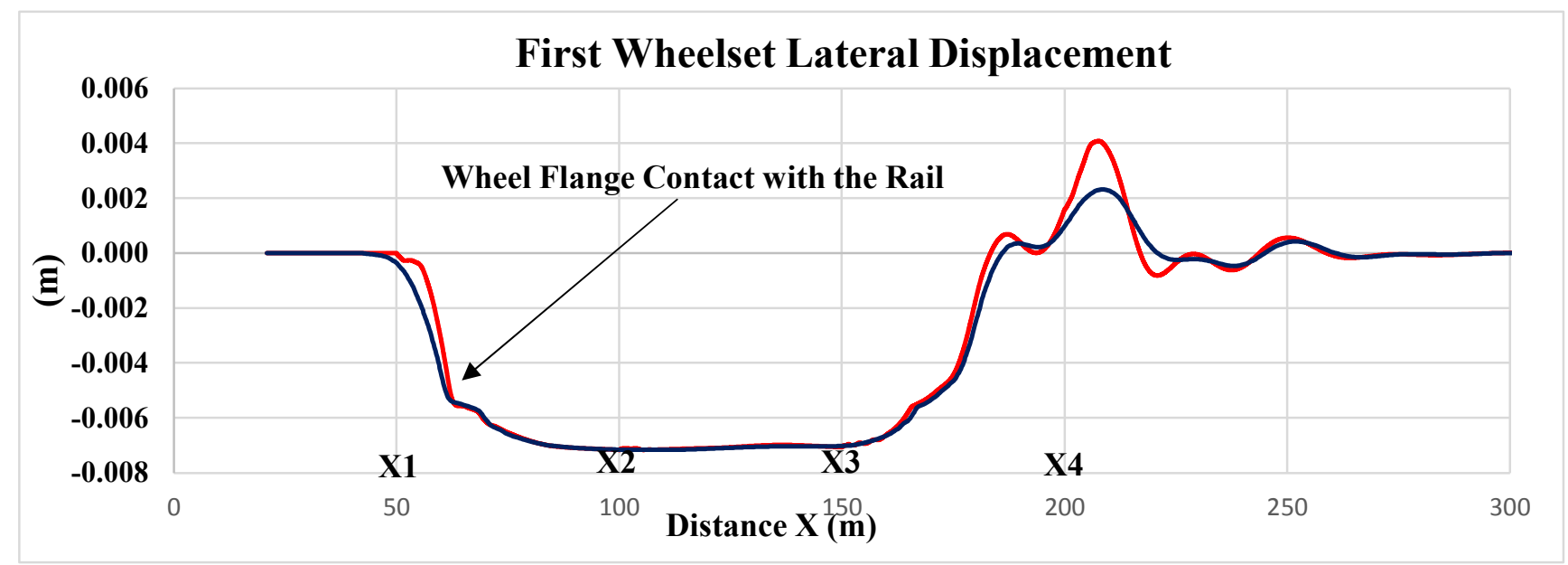

Figure 6. Lateral displacement of the first wheelset measured at rail level in the track plane.

The Figure 7 shows the same comparison for the lateral acceleration of the first bogie. There are no more perturbations at junctions when using doucines (black line).

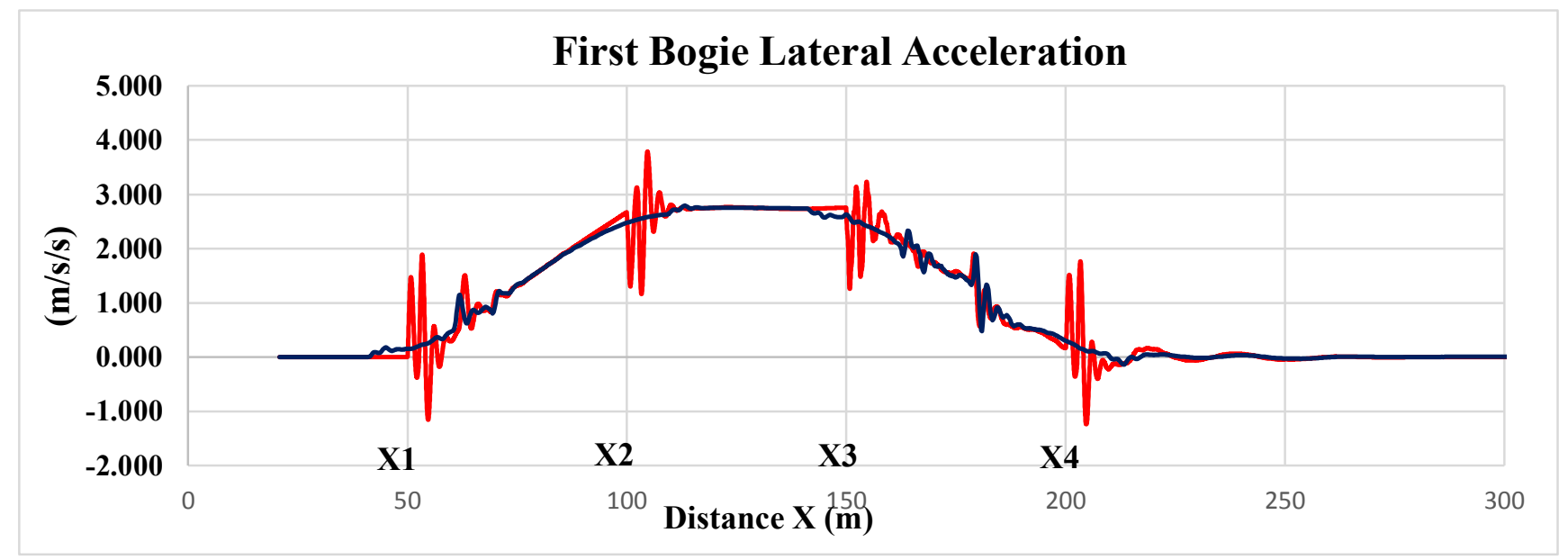

Figure 7. Comparison of bogie lateral accelerations with and without doucines (red line).

The Figure 8 shows the same comparison for the yaw acceleration of the first bogie. The large perturbations at junctions (red line) are removed using doucines (black line).

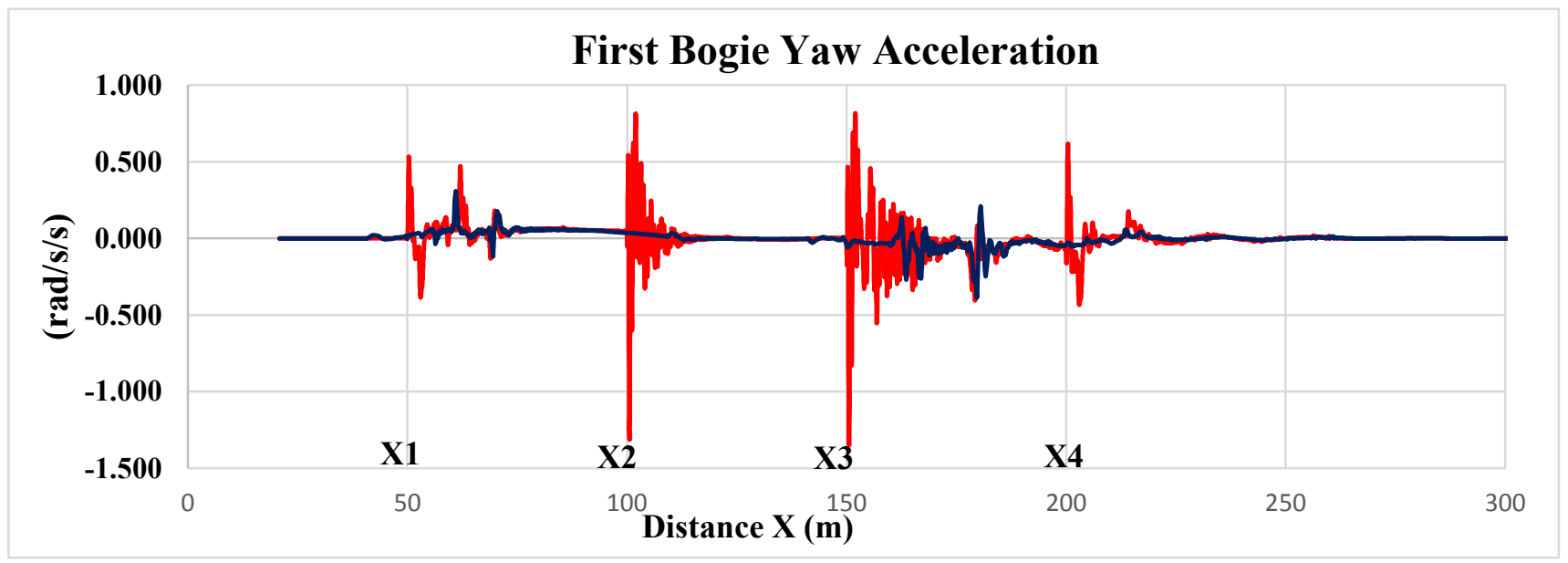

Figure 8. Comparison of bogie yaw accelerations with and without doucines. 


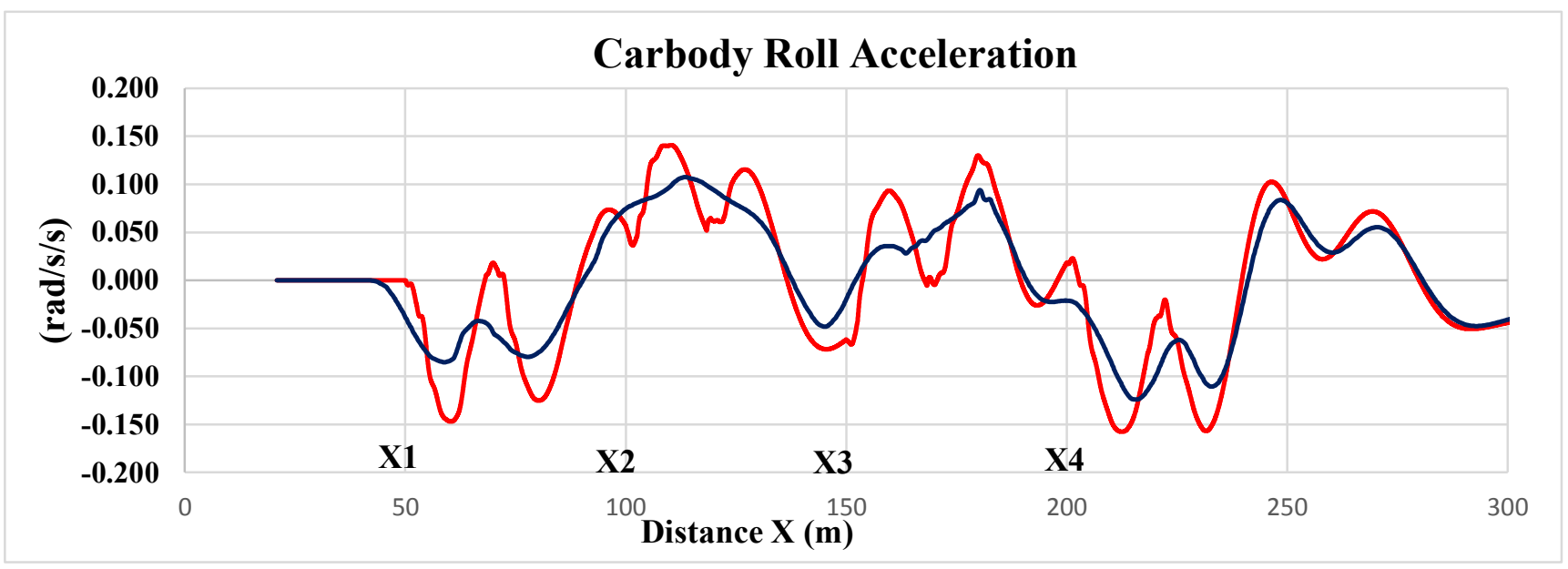

Figure 9. Comparison of carbody roll acceleration with and without doucines (red line).

\section{Conclusions}

We have shown in this paper that the linear spiral theory used for drawing railway lines is not complete because in practice smoothing adjustments are made at track segment junctions according to unspecified methods. These adjustments are called 'doucines' by railway engineers and are necessary to avoid dynamical train perturbations at junctions.

Not knowing a definition of these doucines, railway dynamical codes were obliged up to now to ignore them at the expense of unwanted large perturbations of calculated accelerations as demonstrated by red lines in Figures 5-9.

To avoid these perturbations, the paper presented new analytical definitions of doucines using trigonometric functions and intended to play the same role as is done in real tracks without modifying the track layout. The new doucine definitions deal with curvatures and bank angle only like is practiced for spirals definitions so that it could be easily realized on groundworks without modifying the line layout.

The paper developed the calculation of integration constants necessary to assure a perfect continuity at junctions between doucines and spiral segments.

By developing new doucines into the code OCRECYM that uses the French technique of space transformation developed for TGV studies, we have demonstrated that it fulfills its goals of totally removing the large acceleration perturbations calculated by the code without doucines.

The transformation of actual global space into the imaginary space has been explained and illustrated in the Figure 1.

\section{Acknowledgements}

This work benefitted from discussions with professor Shabana, doctor Sany, doctor El Sibaïe and miss Hao Ling in the frame of Hao Ling paper [12].

\section{References}

[1] Kalker J. J., "Three-Dimensional Elastic Bodies in Rolling Contact", 1st Ed., Kluwer Academic Publishers, Dordrecht/Boston/London, 1990.

[2] Courtin, J. and Pascal, J. P., "Comprehensive Vehicle Testing with the Help of Numerical Modelling". Institution of Mechanical Engineers-(London-March 23 1994).

[3] Kufver Bj., « Mathematical description of railway alignments and some preliminary comparative studies", Swedish National Road and Transportation Research Institute, VTI rapport 420A, 1997.

[4] Klauder L., Chrismer S., Elkins J., "Improved Spiral Geometry for High-Speed Rail and Predicted Vehicle Response" Transportation Research Record Journal of the Transportation Research Board 1785 (1): 41-49. DOI: 10.3141/1785-06, 2002.

[5] Zboiński K., Woźnica P., "Optimisation of polynomial railway transition curves of even degrees", Archives of Transport 35 (3): 71-86, 2015. DOI: $10.5604 / 08669546.1185194$.

[6] Prud'home, A., "Forces and Behavior of Railroad Tracks at Very High Train Speeds; Standards Adopted by SNCF for its Future High Speed Lines (250 to $300 \mathrm{~km} / \mathrm{h}$ )", in Railroad Track Mechanics and Technology, edited by A. D. Kerr, Pergamon Press, Oxford, UK. 1978.

[7] Ayasse J. B., «Dynamique ferroviaire en coordonnées curvilignes et tracé de voie»-2003, book, ISBN: 9782857825753 .

[8] Pascal J. P. 1, "Analysis of the behavior of unstable railway wagons using multibody dynamical codes", 2nd European Nonlinear Oscillation Conference, Prague, September 9-13 1996.

[9] Pascal J. P., Sauvage G., "New Method for reducing the Multicontact Wheel/rail Problem to one equivalent Rigid Contact Patch," Proceedings 12th IAVSD-Symposium, Lyon, August 26-30, 1991.

[10] Pascal J. P., Marquis B., "Rotational equations usable for railway wheelsets". 2014, Vehicle System Dynamics, Vol. 52, pp. 390-409. 
[11] Pascal, J. P., Sany, J. R, Dynamics of an Isolated Railway Wheelset with Conformal Wheel-Rail Interactions. Vehicle System Dynamics, Vol. 54, pp. 1947-1969. 2019.

[12] Ling, H., and Shabana, A. A., 2020, "Numerical Representation of Railroad Track Geometry Using Euler Angles", Technical Report \# MBS2020-3-UIC, Department of Mechanical Engineering, The University of Illinois at Chicago, 2020.
[13] J.P. Pascal, F. Jourdan-(2007) "The rigid Multi-Hertzian Method as applied to conformal Contacts" Proceedings of ASME DETC 2007-34379-Las Vegas, Nevada, USA.

[14] Jean Alias, La Voie Ferrée : techniques de construction et d'entretien, 2e éd., Paris : Eyrolles, 1984.

[15] Szabolcs Fischer, "Comparison of railway track transition curves”, Pollack Periodica 4 (3): 99-110, December 2009. 